\title{
Potentiometric detection and removal of copper using porphyrins
}

\author{
Dana Vlascici ${ }^{1}$, Iuliana Popa ${ }^{2}$, Vlad A Chiriac ${ }^{1}$, Gheorghe Fagadar-Cosma ${ }^{3}$, Horia Popovici ${ }^{1}$ \\ and Eugenia Fagadar-Cosma ${ }^{4^{*}}$
}

\begin{abstract}
Background: Copper is an essential trace element with a great importance in industry, environment and biological systems. The great advantage of ion-selective sensors in comparison with other proposed techniques is that they are measuring the free metal ion activity which is responsible for their toxicity. Porphyrins are known to be among the best ionophores in formulation of ion-selective sensors.

Results: A symmetrically substituted meso-porphyrin, namely: 5,10,15,20-tetrakis(4-allyloxyphenyl)porphyrin (TAPP) was used in the construction of a new copper selective-sensor and was also tested for the removal of copper from waste waters. The potentiometric response characteristics (slope and selectivity) of copper-selective electrodes based on TAPP in o-nitrophenyloctylether (o-NPOE), dioctyl phtalate (DOP) and dioctyl sebacate (DOS) plasticized with poly(vinyl chloride) membranes are compared.

Conclusions: The best results were obtained for the membrane plasticized with DOP. The sensor has linear response in the range $1 \times 10^{-7}-1 \times 10^{-1} \mathrm{M}$ with $28.4 \pm 0.4 \mathrm{mV} /$ decade near-Nernstian slope towards copper ions and presents good selectivity. Due to its chelating nature, the same porphyrin was also tested for the retention of copper from synthetic copper samples, showing a maximum adsorption capacity of $280 \mathrm{mg} / \mathrm{g}$.
\end{abstract}

Keywords: Porphyrins, lon-selective electrode, Potentiometry, Copper, PVC membrane, Detection, Removal

\section{Background}

Trace metals are toxic for many life forms when their concentration exceeds a certain limit. This is the reason why their presence in the environment is an important problem and must be precisely monitored. Copper is an essential trace element with a great importance in industry, environment and biological systems. Considered to be the second toxic metal to aquatic life, copper appears in waters and wastewaters from mining industries, refineries, paper and dyeing. Besides, in the recycling process of Li-batteries technical developments regarding $\mathrm{Ni}, \mathrm{Co}$ and $\mathrm{Mn}$ recovery implies copper monitoring in synthetic leach liquor resulted from reductive leaching. Due to the increased interest in environmental protection, both its detection and removal are very important and many methods were used during the time for this purpose.

\footnotetext{
* Correspondence: efagadar@yahoo.com

${ }^{4}$ Institute of Chemistry Timisoara of Romanian Academy, M. Viteazul Ave. 24 300223 Timisoara, Romania

Full list of author information is available at the end of the article
}

Several techniques were used for copper monitoring such as: atomic absorption spectrometry (AAS), UV-Vis spectrometry and inductively coupled plasma atomic emission spectrometry (ICP-AES), high performance liquid chromatography (HPLC), anodic stripping voltammetry, cyclic voltammetry [1-5]. Generally, these methods requires expensive instruments, qualified personnel, sample pretreatment and are hard to use in environmental conditions.

The potentiometric method with ion-selective sensors was widely developed in the last years due to its simplicity, low cost and fast analysis and a lot of the reported sensors were used in the environmental analysis [6]. The great advantage of ion-selective sensors is that they are measuring the free metal ion activity which is responsible for their toxicity. This is the reason why a lot of copperselective sensors based on different ionophores were reported. Several organic compounds, such as: 1-(2hydroxybenzylidene) thiosemicarbazide [7], Schiff bases $[8,9]$, 2-mercaptobenzoxazole [10], bezo-substituted macrocyclic diamide [11], 6-methyl-4-(1-phenylmethylidene) amino-3-thioxo-1,2,4-triazin-5-one [12], porphyrin derivatives
(C) Chemistry Central

(c) 2013 Vlascici et al.; licensee Chemistry Central Ltd. This is an Open Access article distributed under the terms of the Creative Commons Attribution License (http://creativecommons.org/licenses/by/2.0), which permits unrestricted use, distribution, and reproduction in any medium, provided the original work is properly cited. 
[13], cyclic tetrapeptide derivatives [14], 7-hydroxy-3-(2methyl-2,3-dihydrobenzo[d]thiazol-2-yl)-2H-chromen-2one [15], tetraazacyclotetradecane derivative [16], dimethyl 4,4'-(o-phenylene)bis(3-thioallophanate) [17], succinimide derivative [18], polyindole [19] were tested as ionophores.

For copper removal, many materials and waste materials were reported in the literature [20-26]. The efficiency of removing the metals from wastewaters by adsorption method depends on the physical and chemical composition of the adsorbents.

In the present paper, 5,10,15,20-tetrakis(4-allyloxyphenyl) porphyrin (TAPP) (Scheme 1) was used in the formulation of a new copper-selective sensor and also tested for the removal of copper from synthetic waste waters. The best obtained sensor has a linear response in the in the range $1 \times 10^{-7}-1 \times 10^{-1} \mathrm{M}$ with near-Nernstian slope of $(28.4 \pm 0.4)$ $\mathrm{mV} /$ decade towards copper ions, in a $\mathrm{pH}$ range from 2 to 8 , with a detection limit of $9 \times 10^{-8} \mathrm{M}$. The removal tests were conducted using $5 \mathrm{mg}$ of the same TAPP porphyrin and two copper synthetic samples of 20 and $50 \mathrm{mg} / \mathrm{L}$ concentrations. The maximum adsorption capacity was of $280 \mathrm{mg} / \mathrm{g}$.

\section{Results and discussion Detection tests Working concentration range and slope}

The behaviour of any ion-selective sensor depends on the nature and structure of the ionophore used in the membrane composition. Due to the fact that free porphyrins have donor atoms in their structure, the expectations are to have good affinity to transition metals ions. This was proved by several papers reported in the literature $[13,27,28]$ that mention different porphyrins as sensing material. Besides the critical role of the ionophore, the nature of the plasticizers having different dielectric constants influence the mobility of the ionophore in the membrane phase. The selection of the best plasticizer can improve the sensor potentiometric answer in terms of sensitivity and sometimes also of selectivity. There are some reports which recommend lower dielectric constant plasticizers for some divalent metal selective sensors [14] and others in which the best results were obtained by using plasticizers characterized by big dielectric constants [18]. In this respect, this work was focused on obtaining and comparatively presentation of three sensors having the same weight

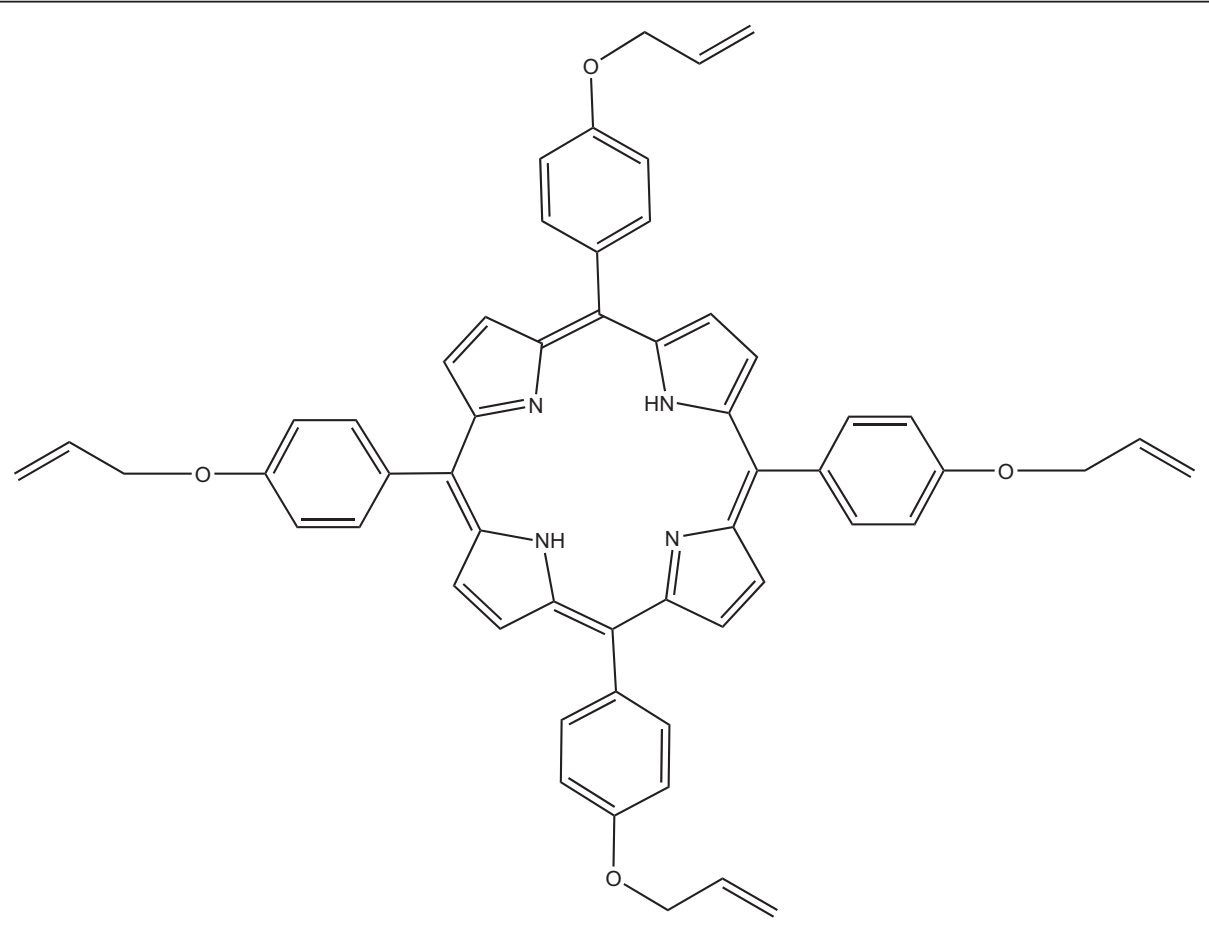

Scheme 1 The structure of the TAPP porphyrin. The figure presents the chemical structure of 5,10,15,20-tetrakis(4-allyloxyphenyl) porphyrin (TAPP) which was used in the paper as ionophore in a new copper-selective sensor and as adsorbent for copper removal from synthetic samples. 
percentage composition of the membrane, but using three different plasticizers: sensor A - plasticized with $o$-nitrophenyloctylether (o-NPOE, $\varepsilon=24)$, sensor B plasticized with dioctyl phtalate (DOP, $\varepsilon=7$ ) and sensor $\mathrm{C}$ - plasticized with dioctyl sebacate (DOS, $\varepsilon=4$ ).

The three sensors were tested in copper solutions from $10^{-7}-10^{-1} \mathrm{M}$ and the obtained results are presented in Figure 1 and Table 1. Analyzing the results, it seems that all of them are copper-selective, having near-Nernstian slopes in different concentration ranges. Sensor B, plasticized with DOP works in the widest concentration range from $1 \times 10^{-7}-1 \times 10^{-1} \mathrm{M}$, with a slope of $(28.4 \pm 0.4) \mathrm{mV} /$ decade.

From the obtained data it can be highlighted that there is no specific rule in choosing the plasticizer due to the fact that DOP has medium values of the dielectric constant comparatively with those of NPOE and DOS, so that selecting of one plasticizer should be made after performing tests.

\section{Effect of interfering ions}

The selectivity coefficients show the influence of the interfering ions on the potential response of the sensor. They were determined by separate solution method using equation (1) and describe the preference of the sensor for the primary ion $\left(\mathrm{Cu}^{2+}\right)$ relative to the interfering ions, which in our case were: monovalent $\left(\mathrm{Na}^{+}, \mathrm{Li}^{+}\right)$, divalent $\mathrm{CNi}^{2+}, \mathrm{Mn}^{2+}, \mathrm{Co}^{2+}, \mathrm{Zn}^{2+}, \mathrm{Pb}^{2+)}$ and trivalent $\left(\mathrm{Fe}^{3+}\right.$ and $\left.\mathrm{Al}^{3+}\right)$. The obtained values are presented in Table 2.

The data presented in Table 2 put into evidence that also in the terms of selectivity the best results were obtained for sensor B, having the membrane plasticized with DOP. The sensor has very good selectivity in comparison with the other tested cations and was further used in all the determinations.

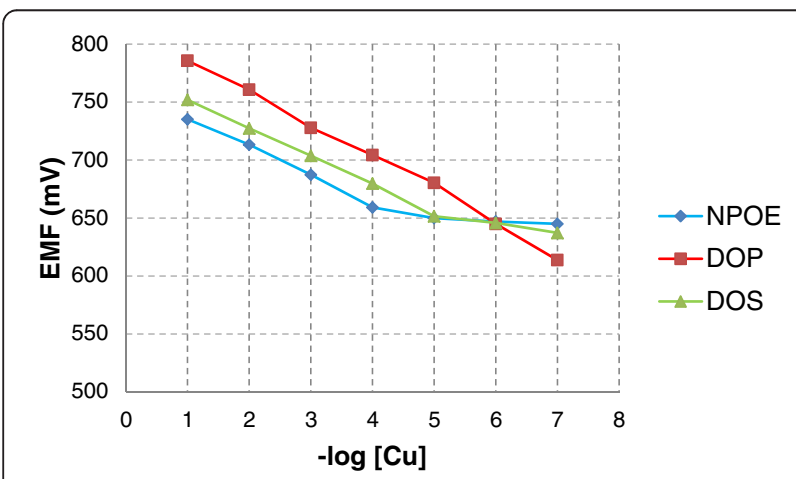

Figure 1 The potentiometric copper responses of electrodes AC. The figure presents the potentiometric responses of the new obtained sensors based on TAPP plasticized with A - NPOE, B - DOP and C - DOS
Table 1 Potentiometric response characteristics of the copper-selective sensors A-C

\begin{tabular}{ccccc}
\hline Sensor & $\begin{array}{c}\text { Working conc. } \\
\text { range }(\mathbf{M})\end{array}$ & $\begin{array}{c}\text { Slope }(\mathbf{m V} / \\
\text { decade) }\end{array}$ & $\begin{array}{c}\text { Detection limit } \\
(\boldsymbol{\mu M})\end{array}$ & $\mathbf{R}^{\mathbf{2}}$ \\
\hline A & $5 \times 10^{-5}-1 \times 10^{-1}$ & $(26.0 \pm 0.3)$ & 0.8 & 0,9969 \\
B & $1 \times 10^{-7}-1 \times 10^{-1}$ & $(28.4 \pm 0.4)$ & 0.09 & 0,9972 \\
C & $1 \times 10^{-5}-1 \times 10^{-1}$ & $(24.8 \pm 0.4)$ & 8.0 & 0,9989 \\
\hline
\end{tabular}

The table presents the working concentration range $(\mathrm{M})$, slope $(\mathrm{mV} /$ decade of activity) and detection limit $(\mu \mathrm{M})$ of the obtained sensors.

From Table 2, it results that the sensor $\mathrm{A} \mathrm{has} \mathrm{Fe}^{3+}$ as interfering ion, but it could not be declared as an ironselective sensor due to the values of the slopes which are sub-Nernstian.

\section{Effect of $\mathrm{pH}$}

The $\mathrm{pH}$ function of sensor $\mathrm{B}$ was obtained in solutions having different values of the $\mathrm{pH}$ and is presented in Figure 2. The potential of the sensor determined as a function of $\mathrm{pH}$ remains constant over the $\mathrm{pH}$ range from 2 to 8 , which may be taken as the working $\mathrm{pH}$ range of the sensor.

\section{Response time and lifetime}

The average time for the copper-selective electrode to reach $95 \%$ of the final potential value after successive immersion of the electrode in a series of copper ion solutions, each having a 10-fold difference in concentration, was measured. The response time from $10^{-3}$ to $10^{-2} \mathrm{M}$ copper solutions was of $10 \mathrm{~s}$, but it became longer for diluted solutions.

One of the most important characteristics of a sensor is its lifetime. In our case, the sensor having the membrane plasticized with DOP has also the best lifetime, of 6 weeks. During this period of time no significant change of the potential was noticed. The stability and reproducibility of the best obtained sensor were also tested. The standard deviation of 15 replicate measurements made for the $1 \times 10^{-3} \mathrm{M}$ solution was $\pm 0.4 \mathrm{mV}$.

The potentiometric response characteristics of the present sensor comparatively to those of some other sensors reported in the literature are presented in Table 3.

\section{Analytical applications}

\section{Determination of copper from synthetic solutions}

For analytical application, the sensor was tested for copper-detection in two synthetic samples, comparatively to the AAS method. The samples of 20 and $50 \mathrm{mg} / \mathrm{L}$ copper were further used for the removal tests using as adsorbent the same TAPP porphyrin. The results are presented in Table 4 for five replicates and they were found to be in close agreement. 
Table 2 Selectivity coefficients of the obtained sensors

\begin{tabular}{cccc}
\hline Interfering ion $(\mathbf{X})$ & Electrode $\mathbf{A}$ & Electrode $\mathbf{B}$ & Electrode $\mathbf{C}$ \\
\hline $\mathrm{Ni}^{2+}$ & -4.38 & -5.56 & -5.84 \\
$\mathrm{Mn}^{2+}$ & -1.60 & -3.28 & -1.03 \\
$\mathrm{Co}^{2+}$ & -3.67 & -4.16 & -2.99 \\
$\mathrm{Fe}^{3+}$ & +1.27 & -0.80 & -0.92 \\
$\mathrm{Na}^{+}$ & -1.70 & -1.68 & -1.87 \\
$\mathrm{Li}^{+}$ & -2.33 & -3.74 & -2.08 \\
$\mathrm{Zn}^{2+}$ & -1.00 & -2.27 & -3.19 \\
$\mathrm{~Pb}^{2+}$ & - & -1.26 & - \\
$\mathrm{Al}^{3+}$ & - & -2.73 & -
\end{tabular}

The table presents the selectivity coefficients of the obtained sensors calculated using equation (1) towards a number of 9 cations: $\mathrm{Ni}^{2+}, \mathrm{Mn}^{2+}, \mathrm{Co}^{2+}$ $\mathrm{Pb}^{2+}, \mathrm{Zn}^{2+}, \mathrm{Fe}^{3+}, \mathrm{Al}^{3+}, \mathrm{Na}^{+}$and $\mathrm{Li}^{+}$.

\section{Determination of copper from spent lithium ion batteries}

The synthetic leach liquor composition was: $50 \mathrm{~g} / \mathrm{L}$ of $\mathrm{Co}, 10 \mathrm{~g} / \mathrm{L}$ of $\mathrm{Li}, 7 \mathrm{~g} / \mathrm{L}$ of $\mathrm{Al}, 5 \mathrm{~g} / \mathrm{L}$ of $\mathrm{Ni}, 2 \mathrm{~g} / \mathrm{L}$ of $\mathrm{Fe}$, $3 \mathrm{~g} / \mathrm{L}$ of $\mathrm{Cu}, 1.5 \mathrm{~g} / \mathrm{L}$ of $\mathrm{Mn}$. Due to the ionic strength of the synthetic solution, sodium nitrate was added to copper samples to brought them to the same ionic strength [29]. The obtained results using the sensor based on three measurements were of $2.97 \pm 0.05 \mathrm{~g} \mathrm{Cu} / \mathrm{L}$.

\section{Removal tests}

Due to the fact that 5,10,15,20-tetrakis(4-allyloxyphenyl) porphyrin was found to be a good ionophore for copper (II) ions, we have tried to use the same TAPP porphyrin as copper adsorbent material. For this purpose, the two synthetic samples used in the analytical application of the sensor, of 20 and $50 \mathrm{mg} / \mathrm{L} \mathrm{Cu}^{2+}$ were further used for the adsorption experiment. The adsorption rate has been analysed using equation (2) and plotted in Figure 3.

The copper concentration was increased from 20 to $50 \mathrm{mg} / \mathrm{L}$ to obtain the maximum removal capacities for the targeted copper ions. High removal rates were obtained at the beginning of the experiment and the

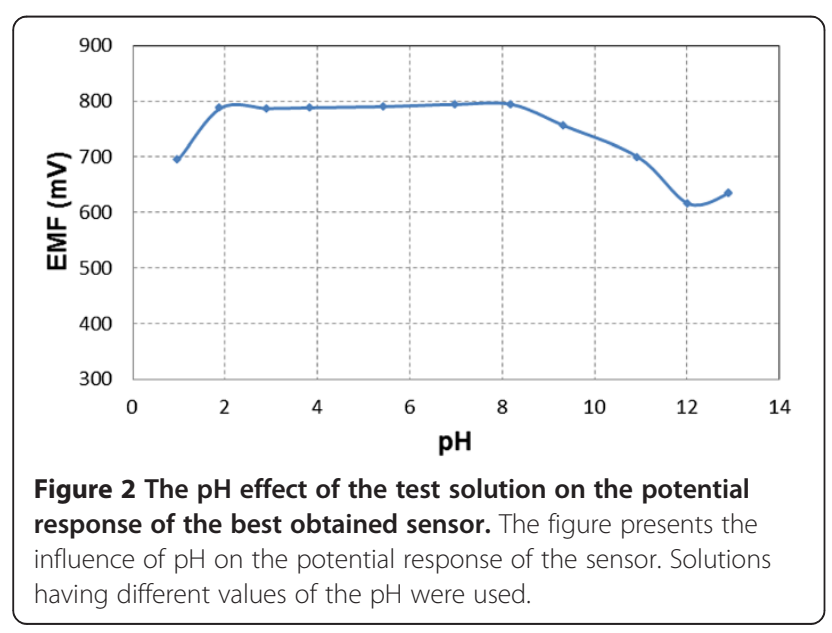

Table 3 Response characteristics of the proposed sensor comparatively to other similar electrodes presented in the literature

\begin{tabular}{|c|c|c|c|c|}
\hline Ref. & $\begin{array}{l}\text { Linear range } \\
\text { (M) }\end{array}$ & $\begin{array}{c}\text { Slope }(m V / \\
\text { decade) }\end{array}$ & $\begin{array}{l}\text { Response } \\
\text { time (s) }\end{array}$ & $\begin{array}{l}\text { Detection } \\
\text { limit (M) }\end{array}$ \\
\hline$[7]$ & $1 \times 10^{-5}-1 \times 10^{-1}$ & $28.6 \pm 0.4$ & 25 & $5.4 \times 10^{-6}$ \\
\hline [8] & $1 \times 10^{-6}-1 \times 10^{-1}$ & $29.8 \pm 0.7$ & 15 & $6.0 \times 10^{-7}$ \\
\hline [9] & $1 \times 10^{-8}-5.7 \times 10^{-}$ & - & 150 & $8.8 \times 10^{-9}$ \\
\hline$[10]$ & $5 \times 10^{-6}-1.6 \times 10^{-}$ & $29.2 \pm 2.0$ & $<10$ & $2 \times 10^{-6}$ \\
\hline$[11]$ & $1 \times 10^{-7}-1 \times 10^{-1}$ & $27.9 \pm 0.8$ & $<30$ & $7,8 \times 10^{-8}$ \\
\hline$[12]$ & $1 \times 10^{-6}-1 \times 10^{-1}$ & $29.2 \pm 0.4$ & - & $30,5 \mu \mathrm{g} / \mathrm{L}$ \\
\hline$[13]$ & $\begin{array}{c}4.4 \times 10^{-6}-1 \times 10^{-} \\
1\end{array}$ & 29.3 & 8 & 0.28 mg/L \\
\hline$[14]$ & $1 \times 10^{-6}-1 \times 10^{-2}$ & $30.2-25.9$ & $<15$ & $\begin{array}{c}0.05-0.13 \mathrm{mg} / \\
\mathrm{L}\end{array}$ \\
\hline$[15]$ & $1 \times 10^{-6}-1 \times 10^{-1}$ & $29.6 \pm 0.3$ & 13 & $7.9 \times 10^{-7}$ \\
\hline$[16]$ & $1 \times 10^{-6}-1 \times 10^{-1}$ & 28.8 & $10-40$ & $7 \times 10^{-7}$ \\
\hline$[17]$ & $9.8 \times 10^{-6}-1 \times 10^{-}$ & 30.3 & 20 & - \\
\hline$[18]$ & $1 \times 10^{-5}-1 \times 10^{-2}$ & 37.6 & 0.25 & $4.4 \times 10^{-6}$ \\
\hline $\begin{array}{l}\text { This } \\
\text { work }\end{array}$ & $1 \times 10^{-7}-1 \times 10^{-1}$ & $28.4 \pm 0.4$ & 10 & $9 \times 10^{-8}$ \\
\hline
\end{tabular}

equilibrium was attained in about $60 \mathrm{~min}$. After that time, a plateau was established. The maximum adsorption was of $280.2 \mathrm{mg}$ of copper per gram of adsorbent (TAPP). The distribution coefficients, which show the affinity of the adsorbent towards the copper ions, were calculated according to equation (3) and the removal capacities, according to equation (4). All the values are listed in Table 5.

Analysing the values, it results that TAPP can also be used with good results as an efficient adsorbent for copper(II) ions.

\section{Conclusions}

The detection and removal of copper ions using 5,10,15,20-tetrakis(4-allyloxyphenyl)porphyrin (TAPP) was investigated. Porphyrin (TAPP) was embedded as ionophore in a PVC matrix, using dioctyl phtalate (DOP) as plasticizer, for obtaining a new copperselective sensor. The resulted sensor is characterized by good sensitivity, very good selectivity and short response time of $10 \mathrm{~s}$. The electrode was used for the potentiometric detection of copper in synthetic samples with a good precision level. The same TAPP porphyrin was tested for the retention of copper from synthetic copper samples with a maximum adsorption capacity of $280 \mathrm{mg} / \mathrm{g}$. 
Table 4 Determination of copper in synthetic samples

\begin{tabular}{cccc}
\hline $\begin{array}{c}\text { Copper sample } \\
(\mathbf{m g} / \mathbf{L})\end{array}$ & $\begin{array}{c}\text { Found by } \\
\text { electrode }(\mathbf{m g} / \mathbf{L})\end{array}$ & $\begin{array}{c}\text { Found by } \\
\text { AAS }(\mathbf{m g} / \mathbf{L})\end{array}$ & Recovery (\%) \\
\hline 20 & $(19.3 \pm 0.4)$ & $(19.6 \pm 0.2)$ & 98.4 \\
50 & $(49.5 \pm 0.5)$ & $(49.8 \pm 0.3)$ & 99.4 \\
\hline
\end{tabular}

The table presents the application of the best obtained sensor in detection of copper from two different synthetic samples of 20 and $50 \mathrm{mg} / \mathrm{L}$ copper concentration, comparatively with those obtained by AAS.

\section{Methods}

\section{Reagents}

The porphyrin 5,10,15,20-tetrakis(4-allyloxyphenyl)porphyrin (TAPP) was synthesized, purified and characterized in accordance with previously published procedures [30]. For membrane preparation, poly(vinyl)chloride (PVC) high molecular weight, bis(2-ethylhexyl)sebacate (DOS), o-nitrophenyloctylether (NPOE), dioctylphtalate (DOP), sodium tetraphenylborate (NaTPB) and tetrahydrofurane (THF) were purchased from Fluka and Merck. All salts, acids and base were of analytical reagent grade. Double distilled water was used. The performance of each sensor was investigated by measuring its potential in the concentration range $10^{-5}-10^{-1} \mathrm{M}$ of different cationic solutions. In the case of copper(II) the solutions were made in a concentration range up to $10^{-8} \mathrm{M}$. Stock solutions, $0.1 \mathrm{M}$, were prepared by dissolving metal nitrates in double distilled water and standardized if necessary. All working solutions were prepared by gradual dilution of the stock solutions.

\section{Electrode membrane preparation and measurements}

The membranes have the weight percentage composition as follows: $1 \%(0,005 \mathrm{~g})$ ionophore, $33 \%(0,165 \mathrm{~g})$ PVC and $66 \%(0,330 \mathrm{~g})$ plasticizer. Sodium tetraphenylborate was used as additive (20 mol\% relative to ionophore). The electroactive material and the solvent mediator were mixed together, and then the PVC and the appropriate amount of THF (3-5 mL) were added and mixed to obtain a

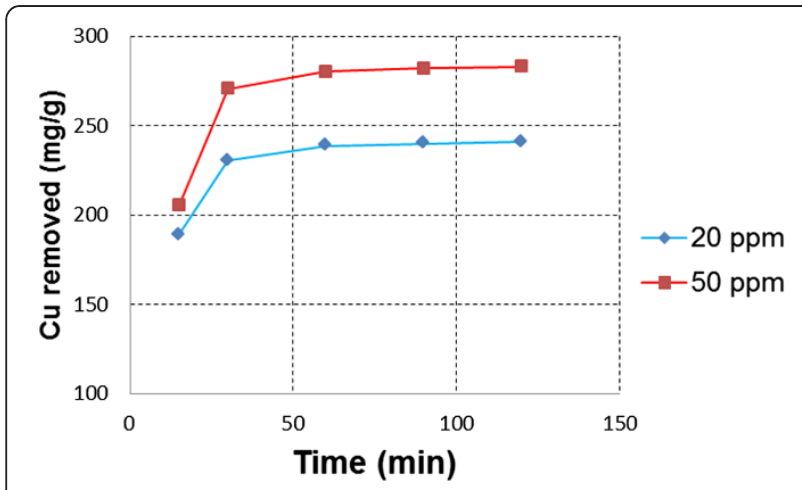

Figure 3 Adsorption isotherms of copper(II) with different initial concentrations on TAPP. The figure presents the adsorption rate for two different initial copper concentrations of 20 and 50 mg/ $L$, at different time intervals.
Table 5 Copper adsorption capacity, distribution coefficient and removal capacity

\begin{tabular}{cccc}
\hline $\mathbf{C}_{\mathbf{0}}(\mathbf{m g} / \mathbf{L})$ & $\mathbf{Q}_{\mathbf{e}}(\mathbf{m g} / \mathbf{g})$ & $\mathbf{K}_{\mathbf{D}}$ & \% Removal \\
\hline 20 & 238,8 & 29,6 & 59,7 \\
50 & 280,2 & 7,8 & 28,0 \\
\hline
\end{tabular}

The table presents the application of 5,10,15,20-tetrakis(4-allyloxyphenyl) porphyrin as adsorbent for copper removal from two different copper solutions in terms of $Q_{e}, K_{D}$ and\% Removal calculated using equations (2), (3) and (4).

transparent solution. This solution was transferred onto a glass plate of $20 \mathrm{~cm}^{2}$, and the THF was allowed to evaporate at room temperature leaving a tough, flexible membrane embedded in a PVC matrix. The round shape pieces of membranes (diameter $=8 \mathrm{~mm}$ ) were cut out and assembled on the Fluka electrode body. The measurements were carried out at room temperature using a Hanna Instruments HI223 $\mathrm{pH} / \mathrm{mV}$-meter by setting up the following cell:

$\mathrm{Ag}|\mathrm{AgCl}| \mathrm{KNO}_{3} \quad(0.1 \mathrm{M}) \mid$ sample|ion-selective membrane|0.01 M KCl|AgCl, Ag.

Prior to EMF measurements, all the sensors were conditioned for $24 \mathrm{~h}$ by soaking in $0.01 \mathrm{M} \mathrm{Cu}^{2+}$ solution. Potentiometric selectivity coefficients were determined according to the separate solution method [31] using the experimental EMF values obtained for $0.01 \mathrm{M}$ of the tested cations and a theoretical slope of $29.6 \mathrm{mV} /$ decade of activity for copper(II) cation, calculated by the equation (1):

$$
\log K_{X, Y}^{p o t}=\frac{\left(E_{Y}-E_{x}\right) \cdot z_{X} \cdot F}{R T \ln 10}+\left(1-\frac{z_{X}}{z_{Y}}\right) \lg a_{X}
$$

The detection limit of each sensor was established at the point of intersection of the extrapolated linear midrange and final low concentration level segments of the calibration plot. The effect of $\mathrm{pH}$ on the potentiometric response of the sensor was obtained by introducing the best obtained sensor in solutions of $\mathrm{HNO}_{3}, \mathrm{NaOH}$ and different buffers, in a $\mathrm{pH}$ range from 1 to 12.92 .

\section{Adsorption test}

The copper removal experiments were carried out by stirring $5 \mathrm{mg}$ of TAPP in $100 \mathrm{~mL}$ of copper solution at $25^{\circ} \mathrm{C}$. Two different copper concentrations of 20 and $50 \mathrm{mg} / \mathrm{L}$ were tested. The solution from each vial was analysed to determine copper concentration after different time intervals. The removal rate was calculated using equation (2):

$$
\mathrm{Q}_{\mathrm{e}}=\frac{\left(\mathrm{C}_{0}-\mathrm{C}_{\mathrm{e}}\right) \times \mathrm{V}}{\mathrm{m}} \mathrm{mg} / \mathrm{g} .
$$

Where $\mathrm{Q}_{\mathrm{e}}$ is the quantity of copper adsorbed on the porphyrin at the time if equilibrium $(\mathrm{mg} / \mathrm{g}), \mathrm{C}_{0}$ is the 
initial concentration of copper in the aqueous solution $(\mathrm{ppm}), \mathrm{C}_{\mathrm{e}}$ is the final cooper concentration at the time of equilibrium (ppm), $\mathrm{m}$ is the mass of porphyrin used as adsorbent (g), $\mathrm{V}$ is the volume of the solution $(\mathrm{L})$.

The distribution coefficient $\left(K_{d}\right)$ shows the affinity of the adsorbent towards copper ions and was calculated using the equation (3)

$$
\mathrm{K}_{\mathrm{D}}=\frac{\mathrm{Q}_{\mathrm{e}}}{\mathrm{C}_{\mathrm{e}}}(\mathrm{L} / \mathrm{g})
$$

The removal capacities of copper ions (\%) taking into consideration the two different initial concentrations, are calculated by equation (4):

$$
\operatorname{Removal} \operatorname{capacity}(\%)=\frac{\left(C_{o}-C_{e}\right)}{C_{o}} \times 100 \text {. }
$$

\section{Competing interests}

The authors declare that they have no competing interest.

\section{Authors' contributions}

DV, IP have made the potentiometric measurements and design the whole concept of research, DV, VAC have made the removal measurements and the initial draft of the manuscript, HP has made the AAS measurements, GFC and EFC have synthesized and characterized the porphyrin ionophore and prepared the final draft of the manuscript. All authors read and approved the final manuscript.

\section{Acknowledgements}

The research leading to these results has received funding from the European Community's Seventh Framework Programme (FP7/2007-2013) under Grant Agreement 266090 (SOMABAT), by UEFISCDI Romanian cofinancing EU-7FP- SOMBAT - Module III- nr. 128 EU/2011, by IPA MIS, Project RoS-NET No. 464 and is a result of collaboration between the coauthors within the project POSDRU/21/1.5/G/38347. All are gratefully acknowledged.

\section{Author details}

${ }^{1}$ West University of Timisoara, Faculty of Chemistry-Biology-Geography, Pestalozzi Street 16, 300115 Timisoara, Romania. ${ }^{2}$ National Institute of Research for Electrochemistry and Condensed Matter, Timisoara, Aurel Paunescu Podeanu Street 144, 300860 Timisoara, Romania. "Politehnica" University of Timisoara, 2 T. Lalescu Street, 300223 Timisoara, Romania. ${ }^{4}$ Institute of Chemistry Timisoara of Romanian Academy, M. Viteazul Ave. 24, 300223 Timisoara, Romania.

Received: 26 April 2013 Accepted: 2 July 2013

Published: 6 July 2013

\section{References}

1. Chan MS, Huang SD: Direct determination of cadmium and copper in seawater using a transversely heated graphite furnace atomic absorption spectrometer with Zeeman -effect background corrector. Talanta 2000, 51:373-380.

2. Camel V: Solid phase extraction of trace elements, A review. Spectrochimica Acta Part B 2003, 58:1177-1233.

3. Cabon JY: Improvement of direct determination of $\mathrm{Cu}$ and $\mathrm{Mn}$ in seawater by GFAAS and total elimination of the saline matrix with the use of hydrofluoric acid. Talanta 2005, 65:402-407.

4. Kaur V, Malik AK: Development of solid phase microextraction-high performance liquid chromatographic method for the determination of copper(II) in environmental samples using morpholine-4-carbodithioate. Ann Chim 2007, 97:1279-1290.

5. Su J, Xu J, Chen Y, Xiang Y, Yuan R, Chai Y: Sensitive detection of copper (II) by a commercial glucometer using click chemistry. Biosens Bioelectron 2013, 45:219-222.
6. De Marco R, Clarke G, Pejcic B: Ion-selective electrode potentiometry in environmental analysis. Review. Electroanal 2007, 19:1987-2001.

7. Ganjali MR, Ghafarloo A, Faridbod F, Norouzi P: Copper-selective PVC membrane sensor. Int J Electrochem Sci 2012, 7:3706-3716.

8. Ganjali MR, Emami M, Salavati-Niasari M: Novel copper(II)-selective sensor based on a new hexadentates Schiff's base. Bull Korean Chem Soc 2002, 23:1394-1398.

9. Aksuner N, Henden E, Yilmaz I, Cukurovali A: A highly sensitive and selective fluorescent sensor for the determination of copper(II) based on a Schiff base. Dye Pig 2009, 83:211-217.

10. Akhound M, Ghaedi M, Tashkourian J: Development of a new copper(II) ion-selective poly(vinyl chloride) membrane electrode based on 2mercaptobenzoxazole. Bull Korean Chem Soc 2005, 26:882-886.

11. Shamsipur M, Mizani F, Saboury AA, Sharghi H, Khalifeh R: Highly selective and sensitive membrane sensors for copper(II) ion based on a newbenzo-substituted macrocyclic diamide $6,7,8,9,10$-hexahydro- $2 \mathrm{H}$ 1,13,4,7,10-benzodioxatriazacyclopentadecine-3,11(4H,12H)-dione. Electroanal 2007, 19:587-596.

12. Zamani HA, Rajabzadeh G, Ganjali MR, Khatami SM: Highly selective and sensitive copper(II) membrane sensors based on 6-methyl-4-(1phenylmethylidene)amino-3-thioxo-1,2,4-triazin-5-one as a new neutral ionophore. Electroanal. 2005, 17:2260-2265.

13. Gupta VK, Jain AK, Maheshwari G, Lang H, Ishtaiwi Z: Copper(II)-selective potentiometric sensors based on porphyrins in PVC matrix. Sens Actuators B 2006, 117:99-106.

14. Hassan SSM, Elnemma EM, Mohamed AHK: Novel potentiometric copper (II) selective membrane sensors based on cyclic tetrapeptide derivatives as neutral ionophores. Talanta 2005, 66:1034-1041.

15. Ganjali MR, Poursaberi T, Khoobi M, Shafiee A, Adibi M, Pirali-Hamedani M, Norouzi P: Copper nano-composite potentiometric sensor. Int J Electrochem Sci 2011, 6:717-726.

16. Petkovic BB, Sovilj SP, Budimir MV, Simonovic RM, Jovanovic VM: A copper (II) ion-selective potentiometric sensor based on N, N', N", N"'-tetrakis(2pyridylmethyl)-1,4,8,11-tetraazacyclotetradecane in PVC matrix. Electroanal. 2010, 22:1894-1900.

17. Gupta VK, Singh LP, Singh R, Upadhyay N, Kaur SP, Sethi B: A novel copper (II) selective sensor based on dimethyl 4,4'-(o-phenylene)bis(3thioallophanate) in PVC matrix. J Mol Liq 2012, 174:11-16.

18. Tutulea-Anastasiu MD, Wilson D, Del Valle M, Schreiner CM, Cretescu I: A solid-contact ion selective electrode for copper(II) using a succinimide derivative as ionophore. Sensors 2013, 13:4367-4377.

19. Pandey PC: Copper(II) ion sensor based on electropolymerized undopedpolyindole modified electrode. Sens Actuat B 1999, 54:210-214.

20. Taraba B, Marsalek R: Immobilization of heavy metals and phenol on altered bituminous coals. Energ Source Part A 2007, 29:885-893.

21. Zaini MAA, Amano Y, Machida M: Adsorption of heavy metals onto activated carbons derived from polyacrylonitrile fiber. $J$ Haz Mat 2010, 180:552-560.

22. Jeong EY, Ansari MB, Mo YH, Park SE: Removal of $\mathrm{Cu}(\mathrm{II})$ from water by tetrakis(4-carboxyphenyl)porphyrin-functionalized mesoporous silica. J Haz Mat 2011, 185:1311-1317.

23. Lima EC, Royer B, Vasghetti JCP, Brasil JL, Simon NM, Dos Santos Jr AA, Pavan FA, Dias SLP, Benvenutti EV, Da Silva EA: Adsorption of Cu(II) on Araucaria angustifolia wastes: Determination of the optimal conditions by statistic design of experiments. J Haz Mat 2007, 140:211-220.

24. Ciolpec M, Lupa L, Negrea A, Davidescu CM, Popa A, Negrea P, Motoc M, David D, Kaycsa D: Kinetic and thermodynamic studies regarding $\mathrm{Cu}(\mathrm{II})$ ions removal from aqueous solution by poly(styrene-divinylbenzene)supported aminophosphonic acids. Rev Chim-Bucharest 2012, 63:49-53.

25. Meena AK, Mishra GK, Rai PK, Rajagopal C, Nagar PN: Removal of heavy metal ions from aqueous solutions using carbon aerogel as an adsorbent. J Haz Mat 2005, 122:161-170.

26. Zheng W, Li XM, Wang F, Yang Q, Deng P, Zeng GM: Adsorption removal of cadmium and copper from aqueous solution by areca-A food waste. J Haz Mat 2008, 157:490-495.

27. Vlascici D, Olenic L, Mihailescu G, Bizerea O, Cosma V, Pica EM, Fagadar Cosma E: Free base porphyrins as ionophores for heavy metal sensors. Sensors 2008, 8:4995-5004.

28. Vlascici D, Fagadar-Cosma E, Popa I, Chiriac V, Augusti MG: A novel sensor for monitoring of iron(III) ions based on porphyrins. Sensors 2012, 12:8193-8203. 
29. Lindner E, Pendley BD: A tutorial on the application of ion-selective electrode potentiometry: an analytical method with unique qualities, unexplored opportunities and potential pitfalls; Tutorial. Anal Chim Acta 2013, 762:1-13.

30. Dudas Z, Enache C, Fagadar-Cosma G, Armeanu I, Fagadar-Cosma E: Hybrid silica-porphyrin materials with tailored pore sizes. Mater Res Bull 2010, 45:1150-1156.

31. Umezawa Y, Buhlmann P, Umezawa K, Tohda K: Potentiometric selectivity coefficients of ion-selective electrodes. Part I Inorganic cations. Pure App/ Chem 2000, 72:1851-2082.

doi:10.1186/1752-153X-7-111

Cite this article as: Vlascici et al:: Potentiometric detection and removal of copper using porphyrins. Chemistry Central Journal 2013 7:111.

\section{Publish with ChemistryCentral and every scientist can read your work free of charge \\ "Open access provides opportunities to our colleagues in other parts of the globe, by allowing anyone to view the content free of charge." \\ W. Jeffery Hurst, The Hershey Company. \\ - available free of charge to the entire scientific community \\ - peer reviewed and published immediately upon acceptance \\ - cited in PubMed and archived on PubMed Central \\ - yours - you keep the copyright \\ Submit your manuscript here: \\ http://www.chemistrycentral.com/manuscript/<smiles>c1ccccc1</smiles> 